\title{
The Complex Role of Neuroinflammation in Glaucoma
}

\author{
Ileana Soto ${ }^{1}$ and Gareth R. Howell ${ }^{1,2}$ \\ ${ }^{1}$ The Jackson Laboratory, Bar Harbor, Maine 04609 \\ ${ }^{2}$ School of Medicine, Tufts University, Boston, Massachusetts 02111 \\ Correspondence: gareth.howell@jax.org
}

Glaucoma is a multifactorial neurodegenerative disorder affecting 80 million people worldwide. Loss of retinal ganglion cells and degeneration of their axons in the optic nerve are the major pathological hallmarks. Neuroinflammatory processes, inflammatory processes in the central nervous system, have been identified in human glaucoma and in experimental models of the disease. Furthermore, neuroinflammatory responses occur at early stages of experimental glaucoma, and inhibition of certain proinflammatory pathways appears neuroprotective. Here, we summarize the current understanding of neuroinflammation in the central nervous system, with emphasis on events at the optic nerve head during early stages of glaucoma.

\begin{abstract}
Claucoma is a complex neurodegenerative $\mathcal{C}$ disease that results in the degeneration of retinal ganglion cells (RGCs) and their axons in the optic nerve. Age and elevation of intraocular pressure (IOP) over baseline are major risk factors for glaucoma (Quigley 1993, 2011). Strong evidence suggests that an early insult occurs to RGC axons at the optic nerve head (ONH) (Jakobs et al. 2005; Schlamp et al. 2006; Howell et al. 2007; Soto et al. 2008; Burgoyne 2011; Quigley 2011; Nickells et al. 2012). The exact mechanisms by which RGC axons are insulted and ultimately degenerate are not clear, although early neuroinflammatory responses by astrocytes, microglia, and other blood-derived immune cells are observed in the $\mathrm{ONH}$, suggesting a primary role of inflammation in glaucoma (Howell et al.
\end{abstract}

2012; Nickells et al. 2012; Tezel 2013). Furthermore, some evidence suggests that other RGC compartments, such as dendrites, synapses, and soma, are impacted early in the disease and that these events may also involve, even be mediated by, inflammatory responses in the retina (Howell et al. 2011a; Nickells et al. 2012; Tezel 2013). Therefore, the role of inflammation in glaucomatous neurodegeneration is currently of great interest.

In this review we focus on the role of inflammation in glaucomatous RGC loss (referred to as neuroinflammation). In particular, we discuss the proposed roles of astrocytes, resident microglia and other monocyte-derived cells in early stages of glaucoma in the optic nerve head. Evidence is suggesting these cell types are criti-

Editors: Eric A. Pierce, Richard H. Masland, and Joan W. Miller

Additional Perspectives on Retinal Disorders: Genetic Approaches to Diagnosis and Treatment available at

www.perspectivesinmedicine.org

Copyright (C) 2014 Cold Spring Harbor Laboratory Press; all rights reserved; doi: 101101/cshperspect.a017269

Cite this article as Cold Spring Harb Perspect Med 2014;4:a017269 
I. Soto and G.R. Howell

cal players in the early neuroinflammatory responses in glaucoma.

\section{NEUROINFLAMMATORY RESPONSES IN THE CNS RELEVANT TO GLAUCOMA}

Although there is still much to be explored, neuroinflammatory responses identified to date in glaucoma show some hallmarks of classic inflammatory responses to disease, injury or infection in the central nervous system (CNS). Therefore, we can learn from what has been studied in other diseases, particularly neurodegenerative diseases. The CNS, which includes the brain, retina, and optic nerve, is an immune privileged tissue (Glass et al. 2010; Lampron et al. 2013); in contrast to other tissues, communication between the CNS and the systemic immune system is relatively limited (Glass et al. 2010; Ransohoff and Brown 2012; Lampron et al. 2013). Therefore, immune responses in the CNS are generally mediated by a limited number of cell types.

\section{Major Players in CNS Immune Responses}

The CNS includes resident astrocytes and microglial cells (collectively termed glial cells) that perform immune surveillance and mediate primary inflammatory responses to infection, disease, or injury. Astrocytes are glial cells that are in contact with neurons, blood vessels and other glial cells to provide an array of functions including metabolic support, modulation of synaptic activity, regulation of extracellular ion concentrations, and maintenance of the bloodbrain barrier (Ullian et al. 2001; Simard and Nedergaard 2004; Iadecola and Nedergaard 2007; Pellerin et al. 2007; Rouach et al. 2008). Microglial cells, myeloid-derived cells that reside in the CNS, are generated from the yolk sac before vascularization and possess phagocytic and antigen-presenting capabilities, although these are more limited than those of peripheral antigen-presenting cells (Ginhoux et al. 2010; Glass et al. 2010; Ransohoff and Brown 2012; Lampron et al. 2013). Blood-derived monocytes, dendritic cells and other immune cells are generally excluded from the CNS parenchyma un- der healthy conditions (Ransohoff and Brown 2012; Ransohoff and Engelhardt 2012). However, following proinflammatory stimulation, glial cells are activated and produce cytokines and chemokines to recruit infiltrating bloodderived immune cells to amplify the inflammatory response in the CNS (Ransohoff et al. 2003; Callahan and Ransohoff 2004).

\section{Triggering Inflammatory Responses: PAMPs, DAMPs, and Their Sensors}

The main role of astrocytes and microglia is to recognize and respond to perturbations in the environment. Perturbations can arise from two major sources: invading microbial pathogens and age- or disease-related stress or injury. Astrocytes and microglial cells possess signaling mechanisms for host defense that are activated by the recognition of structural characteristics found in pathogens, known as pathogen-associated molecular patterns (PAMPs) (Glass et al. 2010; Lampron et al. 2013). Astrocytes and microglial cells also recognize signals released from damaged or stressed cells, known as damageassociated molecular patterns (DAMPs) (Rifkin et al. 2005; Yu et al. 2010; Zhang et al. 2010; Zhu et al. 2011). It has been hypothesized that DAMPs are preexisting intracellular adjuvants that are released when necrotic cell death occurs or when apoptotic cells are not rapidly cleared (Kono and Rock 2008). These DAMPs can also be delivered to the cell surface of damaged cells after injury (Zhu et al. 2011). Molecules identified as bona fide DAMPs include heat shock proteins (HSPs), uric acid, high-mobility group box-1 protein and double stranded DNA (Kono and Rock 2008). The existence of additional DAMPs cannot be ruled out, and efforts are ongoing to identify them. Both PAMPs and DAMPs are recognized by pattern recognition receptors (PRRs) on astrocytes and/or microglia that trigger and mediate the inflammatory response (Fig. 1).

An important class of pattern recognition receptors is the toll-like receptors (TLRs) (Gorina et al. 2009; Downes and Crack 2010; Lehnardt 2010). TLRs can recognize a diverse group of pathogenic molecules that are not present 


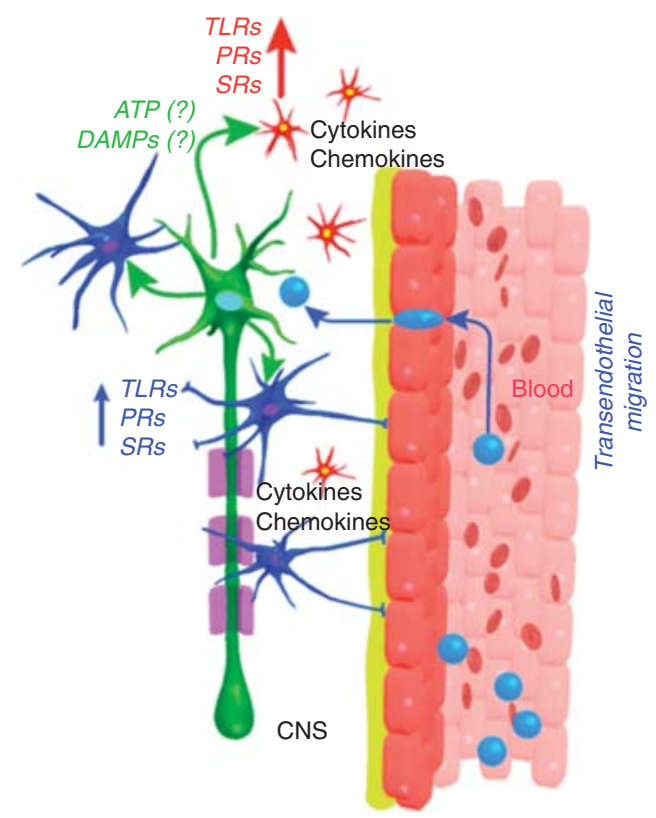

Figure 1. Inflammatory responses in the CNS are mediated by resident astrocytes and microglia. The neurovascular unit comprises neurons (green), astrocytes (blue, with processes) and components of the blood-brain barrier such as endothelial cells (red, vessel). In addition, microglia (red, with processes) sense environmental changes. Glial cells (astrocytes and microglia) express pattern recognition receptors (PRRs) such as toll-like receptors (TLRs), purinergic receptors (PRs) and scavenger receptors (SRs) to respond to DAMPs released by cells during injury or disease. The activation of these receptors promotes proinflammatory signaling that leads to the production of cytokines and chemokines. These cytokines and chemokines induce changes in the endothelial cells and blood-brain barrier integrity, resulting in recruitment of blood-derived immune cells (blue) and amplification of the innate immune response.

in the host (e.g., lipopolysaccharide and viral RNA), but are also able to recognize endogenously derived molecules that are released from injured or dying cells such as HSP60, HSP70 and $\alpha \mathrm{B}$-crystallin (Takeuchi and Akira 2010; Zhang et al. 2010; Ransohoff and Engelhardt 2012). Whereas all thirteen TLRs are expressed on microglial cells, only TLR2, TLR3, TLR4, TLR5, and TLR9 are expressed on astrocytes (Farina et al. 2007). On activation, TLRs recruit the downstream signal adaptor proteins
Neuroinflammation in Glaucoma

MyD88 and TRIF, which lead to the activation of kinases IкB and MAPK and their downstream group of transcription factors that include members of the NF-кB, AP-1 and interferon regulator factor families resulting in the transcription of several amplifiers and effectors (Glass et al. 2010; Takeuchi and Akira 2010). Among these amplifiers and effectors are cytokines, such as tumor necrosis factor (TNF)- $\alpha$, interleukin (IL)-1 $\beta$, and IL-6, as well as an array of chemokines (e.g., CCL2, CXCL1, CXCL10).

A second class of pattern recognition receptor is the NOD-like receptors, specifically the NALP family, which are components of the multiprotein complexes termed the "inflammasome" that can modulate the inflammatory response (Takeuchi and Akira 2010; Ransohoff and Brown 2012). Cooperative interactions between TLRs and the inflammasome lead to the maturation and secretion of cytokines such as IL-1 $\beta$ and IL-18. Other types of pattern recognition receptors include the mannose receptor, scavenger receptor, and the ionic purinergic receptor. The mannose receptor is a C-type lectin that recognizes surfaces that are glycosylated with a mannose moiety (Gazi and Martinez-Pomares 2009) and can trigger immune responses including the activation of the complement cascade (Kerrigan and Brown 2009). Scavenger receptors are involved in the recognition and uptake of oxidized proteins and lipids released by damaged cells (Husemann et al. 2002). The ionic purinergic receptors (such as $\mathrm{P} 2 \mathrm{X} 7 \mathrm{R}$ ) are activated by ATP released from damaged cells and facilitate formation of the inflammasome (Takeuchi and Akira 2010; Ransohoff and Brown 2012).

Under conditions of injury or disease, astrocytes and microglia become reactive and their PRRs are activated, leading to the generation of innate inflammatory mediators that include members of the complement pathway, cytokines, and several chemokines (such as those listed above). Certainly these proinflammatory molecules affect neuronal function and amplify the inflammatory response of microglial cells during pathological conditions (Glass et al. 2010). Activation of proinflammatory mediators by microglia can result in a cascade of 
events, including proliferation, migration, expression of adhesion molecules on endothelial cells, and the promotion of leukocyte infiltration into the CNS parenchyma through the bloodbrain barrier (Ransohoff and Brown 2012).

\section{Transendothelial Migration in the CNS}

Migration (or infiltration) of leukocytes (immune cells) into the CNS is a highly regulated process involving interactions between circulating leukocytes and endothelial cells (Fig. 2) (Ransohoff et al. 2003). Transendothelial migration of leukocytes is a multistep process and involves: (1) tethering and rolling of leukocytes on the endothelial cells; (2) activation of key molecules on both endothelial cells and leukocytes; and finally (3) paracellular or transcellular migration of leukocytes into the CNS. Leukocyte infiltration is a common event in CNS disease and injury, and is thought to occur after chronic stress (Ransohoff et al. 2003; Callahan and Ransohoff 2004; Ransohoff and Brown 2012). Leukocyte infiltration is commonly initiated by the release of cytokines and chemokines from glial cells (Carson et al. 2006; Ifergan et al. 2008). Studies using intravital microscopy found that activation of leukocytes was not sufficient to promote interaction of endothelial cells and leu- kocytes. However, leukocyte tethering was observed when endothelial cells were activated with lipopolysaccharide or TNF- $\alpha$ (Piccio et al. 2002). It is thought that after cytokine stimulation, tethering and rolling occurs as a result of the up-regulation of selectins (e.g., P-selectin) and integrin ligands (e.g., VCAM-1 and ICAM1) on the lumen of endothelial cells that are sensed by selectin ligands (e.g., PSGL1) and integrins (e.g., LFA1) present on the surface of circulating leukocytes (Lampron et al. 2013). These signaling processes between endothelial cells and leukocytes promote the loosening of the tight junctions between the endothelial cells, facilitating migration of leukocytes into the CNS (Ransohoff et al. 2003; Lampron et al. 2013).

The cellular and molecular mechanisms by which transendothelial migration occurs in the CNS during injury and disease are complex and still not completely understood. More research is needed to elucidate the identity and role of these infiltrating cells during neurodegenerative diseases.

\section{The Complement Cascade Modulates Inflammatory Responses}

The complement cascade was originally named as it "complements" immune responses. How-

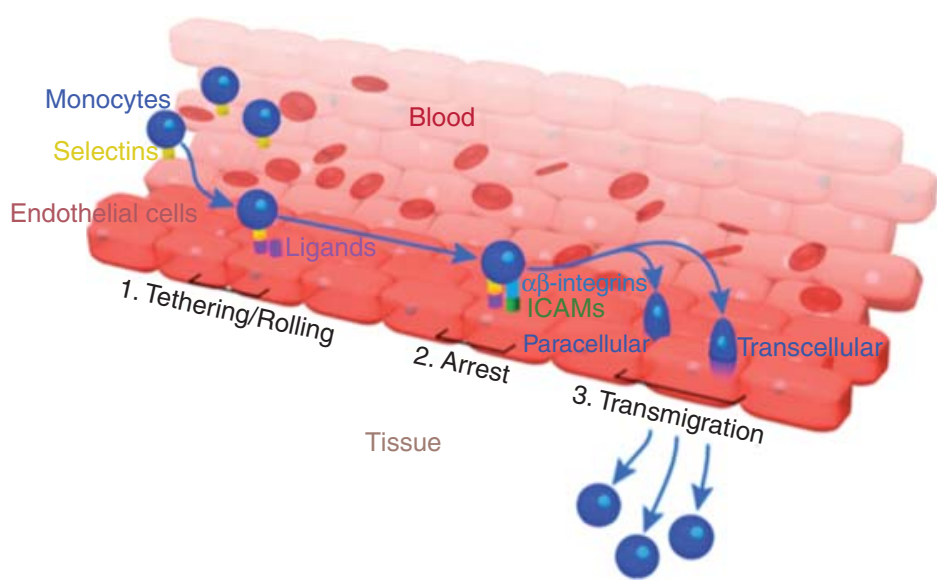

Figure 2. Transendothelial migration in the CNS. Schematic representation of the different steps involved in leukocyte extravasation. Selectin ligands and molecular adhesion molecules that are up-regulated in endothelial cells at the ONH interact with selectins and integrins present at the cell surface of leukocytes, leading to leukocyte infiltration. 
ever, recent and emerging evidence suggests it plays a much more complex role in the CNS in health and disease. Components of the complement cascade play a significant role in immune surveillance and inflammatory processes, both peripherally and in the CNS (Janeway et al. 2001). In addition to its involvement in pathogen targeting and elimination, the complement system is also involved in synapse elimination and clearance of potential mediators of damage or injury (Ricklin et al. 2010; Rosen and Stevens 2010).

The complement system is a cascade of three separate pathways known as the classical, alternative, and lectin pathways (Ricklin et al. 2010). A strong complement response includes opsonization of the foreign pathogen or apoptotic cell/cellular compartment by complement fragments, induction of proinflammatory signaling by anaphylatoxins that recruit macrophages, and enable phagocytosis and the formation of the membrane attack complex (MAC), which leads to the lysis of the targeted cell (Ricklin et al. 2010). The classical pathway is initiated by the $\mathrm{C} 1$ complex that recognizes pathogens or DAMPs, leading to the formation of the C3 convertase that cleaves the $\mathrm{C} 3$ protein to generate the active fragments $\mathrm{C} 3 \mathrm{a}$ and $\mathrm{C} 3 \mathrm{~b}$. C3a induces proinflammatory signaling and $\mathrm{C} 3 \mathrm{~b}$ deposition induces cleavage of the $\mathrm{C} 5$ protein to $\mathrm{C} 5 \mathrm{a}$ and $\mathrm{C} 5 \mathrm{~b}$ by C5 convertases. C5a is a potent anaphylatoxin, whereas $\mathrm{C} 5 \mathrm{~b}$ is a fundamental member of the MAC, a cell lysis-inducing channel. Other complement factors in the MAC are C6, C7, C8, and C9. The C3 convertase is also activated by the alternative and lectin pathways, and all three pathways can result in the activation of the MAC (Ricklin et al. 2010). Activation of the complement system has been observed in the CNS after injury and in neurodegenerative diseases such as Alzheimer's disease, Parkinson's disease, and glaucoma (Bonifati and Kishore 2007).

Beneficial and Damaging Effects of the Immune Response in the CNS

As described above, the immune response is a complex series of events involving resident glial cells (e.g., astrocytes and microglia), components of the blood-brain barrier (e.g., endothelial cells), and infiltrating blood-derived cells (e.g., monocytes). The early immune responses are likely the body's natural attempts to minimize damage after an initial injury or insult in chronic and age-related CNS diseases. Later immune responses, as the disease enters a chronic phase, are likely more detrimental. In some cases, these beneficial and detrimental events involve molecules in the same pathway, such as the complement cascade. Therefore, when considering therapies, it is important to fully understand the beneficial and detrimental natures of inflammatory processes in CNS injury and disease.

\section{NEUROINFLAMMATORY RESPONSES IN GLAUCOMA}

So far, we have described immune responses as they relate generally to the CNS in response to infection, injury, or disease. We now describe what is known about the role of the immune system in glaucoma, and highlight areas for further investigation.

\section{Activation of Astrocytes and Microglia in the Optic Nerve Head in Early Stages of Glaucoma}

Retinal cells and glial cells in the $\mathrm{ONH}$ respond rapidly and early to glaucomatous insults, including elevation of IOP. Changes in astrocyte morphology, such as enlargement of the cell body and processes, as well as up-regulation of cytoskeletal and extracellular matrix proteins, have been observed in the retina and $\mathrm{ONH}$ in human glaucoma (Wang et al. 2002; Inman and Horner 2007; Hernandez et al. 2008; Kompass et al. 2008; Nikolskaya et al. 2009). Several studies have demonstrated that this reactivity and remodeling of astrocytes, and the increased deposition of extracellular matrix occur in early stages of experimental glaucoma (Johnson and Morrison 2009; Howell et al. 2011a; Johnson et al. 2011; Lye-Barthel et al. 2013; Qu and Jakobs 2013). In fact, just a short term elevation of IOP induces rapid and reversible morphological 
changes in astrocytes of the $\mathrm{ONH}$ that include hypertrophy, process retraction, and simplification of the shape without changing gene expression (Sun et al. 2013). Furthermore, changes in gene expression in astrocytes are observed at early stages of experimental glaucoma before RGC axon damage (Johnson et al. 2000, 2011; Howell et al. 2011a; Qu and Jakobs 2013). This early up-regulation of extracellular matrix in astrocytes of the $\mathrm{ONH}$ may function to repair or prevent damage to the blood-brain barrier in response to high IOP. This has been shown in other settings (Sofroniew and Vinters 2010). For instance, inhibition of reactive astrogliosis by the conditional deletion of the STAT3 protein in models of spinal cord injury promotes massive infiltration of blood-derived leukocytes and increased neurodegeneration, suggesting that astrocyte reactivity is a protective response in CNS injury (Okada et al. 2006; Herrmann et al. 2008). Consistent with this idea is the observation that components of the basement membrane of the blood-brain barrier, such as collagen, are up-regulated in the $\mathrm{ONH}$ in human glaucoma and in experimental models of the disease (Hernandez et al. 1990, 1994; Morrison et al. 1990; Johnson et al. 2011). On the other hand, the overexpression of cell adhesion proteins, including several integrins, by astrocytes in glaucoma could also promote the adhesion and migration of immune cells into damaged areas of the ONH (Howell et al. 2011a; Johnson et al. 2011; Tanigami et al. 2012). Furthermore, $\mathrm{ONH}$ astrocytes in human glaucoma and experimental models up-regulate tenascin-C (Pena et al. 1999; Howell et al. 2011a; Johnson et al. 2011), an extracellular matrix glycoprotein that supports proinflammatory responses through TLR4 signaling (Midwood et al. 2009), suggesting a proinflammatory role of astrocytes in glaucoma.

Activation of microglial cells in the $\mathrm{ONH}$ and retina has also been observed in experimental models of glaucoma (Neufeld 1999; Yuan and Neufeld 2001; Johnson and Morrison 2009; Ebneter et al. 2010; Bosco et al. 2011; Taylor et al. 2011). This microglial reactivity is characterized by increased proliferation, increased phagocytic activity (revealed by an increase in the phagocytosis-related protein CD68), changes in morphology, and expression of proinflammatory molecules, such as members of the complement cascade, major histocompatibility complex class I, and major histocompatibility complex class II (Ebneter et al. 2010; Howell et al. 2011a; Bosco et al. 2012). Although the role of microglia in glaucoma progression is not clear, it is notable that the extent of microglia activation is closely related to axonal degeneration in the $\mathrm{ONH}$. In fact, reduction in microglial number is evident when axonal degeneration (but not high IOP) is prevented by radiation treatment of the eye or head in a mouse model of glaucoma (Howell et al. 2012; Bosco et al. 2012).

\section{What Triggers Inflammatory Responses in Glaucoma?}

Early neuroinflammatory responses by astrocytes and microglia occur in glaucoma, but it is not known which stresses or damage-associated molecules trigger the responses. One possibility is that DAMPs are released or presented by stressed or damaged RGC axons in the $\mathrm{ONH}$. In glaucoma, heat shock proteins, a type of DAMP, are up-regulated in response to elevation in IOP (Tezel et al. 2004; Tezel 2011), and levels of a variety of heat shock proteins were also increased in human glaucomatous retinas (Luo et al. 2010). A second possibility is that astrocytes and/or microglia produce DAMPs independent of or before changes in RGCs. One candidate for this is tenascin- $\mathrm{C}$, which is up-regulated in astrocytes of the glaucomatous ONH (Pena et al. 1999; Howell et al. 2011a; Johnson et al. 2011). Tenascin-C is an endogenous activator of the TLR4 in inflammation associated with arthritis (Midwood et al. 2009). Identification of initiator(s) of inflammatory events is a key area of study in glaucoma research.

\section{Inflammatory Signaling Pathways in Glaucoma}

Although the specific triggers for inflammatory responses in glaucoma remain poorly defined, 
inflammatory processes, mediated in part by astrocytes and resident microglia, clearly play a crucial role in glaucoma. Several studies using transcriptional profiling have identified early up-regulation of genes associated with inflammatory pathways in the retina and $\mathrm{ONH}$ in experimental models of glaucoma (Ahmed et al. 2004; Johnson et al. 2007, 2011; Yang et al. 2007; Kompass et al. 2008; Nikolskaya et al. 2009; Panagis et al. 2010; Howell et al. 2011a, 2012). Collectively, these studies showed an up-regulation of inflammatory inducers/sensors (PRRs, e.g., TLRs), transducers (e.g., Mapk, Trif, MyD88) and amplifiers (e.g., Il1, Il6, Tnf, Ccl2) in human glaucoma (Luo et al. 2010; Yang et al. 2011; Tezel et al. 2012) and in early stages of experimental glaucoma (Howell et al. 2011a; Johnson et al. 2011). In our study using DBA/2J mice, an inherited model of glaucoma, we were able to define early molecular changes that occur before detectable loss of RGCs and axons (Howell et al. 2011a). Gene ontology analysis revealed that genes associated with "immune response," "leukocyte activation," and "chemotaxis" were among the genes up-regulated earliest in mice with high IOP but no detectable loss of axons.

Evidence from both human glaucoma patients and animal models of glaucoma suggest that immune responses are mediated, at least in part, by TLRs. For instance, proteomic analysis of glaucomatous human retinas revealed upregulation of TLR signaling (Luo et al. 2010). Expression of TLR2, TLR3, and TLR4 was observed in microglia and astrocytes from glaucomatous retinas. In early stages of DBAJ glaucoma, 11 of the 13 TLRs were up-regulated in the $\mathrm{ONH}$ at early stages of DBA/2J glaucoma (Howell et al. 2011a,b). These included Tlr3, $T l r 7$, and Tlr9, whose proteins detect nucleic acids released from damaged cells, and Tlr2 and Tlr4, whose gene products sense host cell HSPs (Rifkin et al. 2005; Yu et al. 2010; Zhang et al. 2010). The TLR adaptor protein MyD88 and members of the MAPK pathway were also up-regulated in retinas from glaucoma patients and in the ONH of DBA/2J mice (Luo et al. 2010; Howell et al. 2011a,b).

As mentioned previously, engagement of TLRs by DAMPs can lead to the activation of
NF-кB. Not surprisingly, proteomic analysis of glaucomatous retinas from humans and rats found increased expression of kinases such as RIPK, NIK, and IкK that are involved in the activation of the NF-кB pathway (Yang et al. 2011; Tezel et al. 2012). Activation of NF- $\mathrm{B}$ results in the transcription of genes from the IL-1 cytokine family. Secretion of these cytokines can promote production of a secondary cascade of inflammatory cytokines in microglia (e.g., TNF- $\alpha$ ) and astrocytes (e.g., IL-6) that amplifies the immune response by recruiting other cells to the site of damage. In support of this sequence of events, members of the IL-1 family were found to be up-regulated in the ONH at early stages of DBA/2J glaucoma (Howell et al. 2011a,b).

Studies have also suggested an important role for tumor necrosis factor (TNF) family members in the pathogenesis of glaucoma. Increased levels of TNF- $\alpha$ have been found in the aqueous humor, retina, and optic nerve microglia and optic nerve astrocytes from glaucoma patients (Yan et al. 2000; Yuan and Neufeld 2000, 2001; Tezel et al. 2001; Sawada et al. 2010). Activation of the signaling pathway downstream from TNF- $\alpha$ in glaucomatous human retinas has also been reported (Yang et al. 2011). Several ligands and receptors of the TNF family were overexpressed at early stages of DBA/2J glaucoma, although not as early as was observed for the Il1-related cytokines (Howell et al. 2011a,b). Genetic and pharmaceutical inhibition of TNF$\alpha$ activity in experimental models of glaucoma can prevent microglia activation, axonal degeneration and RGC loss (Fig. 3) (Nakazawa et al. 2006; Roh et al. 2012). Another member of the TNF family implicated in glaucoma pathogenesis is the proapoptotic protein Fas ligand, which was found to be damaging to RGCs in DBA/2J glaucoma (Gregory et al. 2011). Inhibition of Fas ligand activity prevented death of RGCs after intraocular injection of TNF- $\alpha$, indicating that Fas ligand mediates TNF- $\alpha$ cytotoxicity in RGCs (Gregory et al. 2011).

In summary, it has been clearly demonstrated that proinflammatory pathways (likely activated by DAMPs) are important contributors to the early progression of glaucoma. Further 
I. Soto and G.R. Howell

A
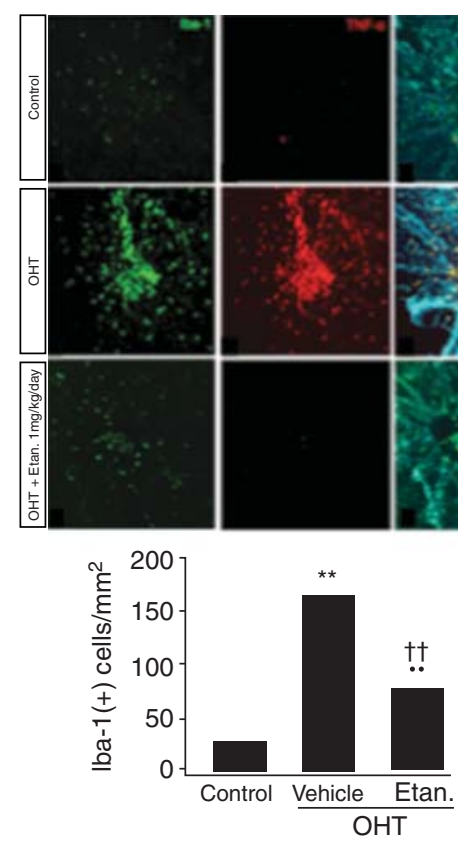

B
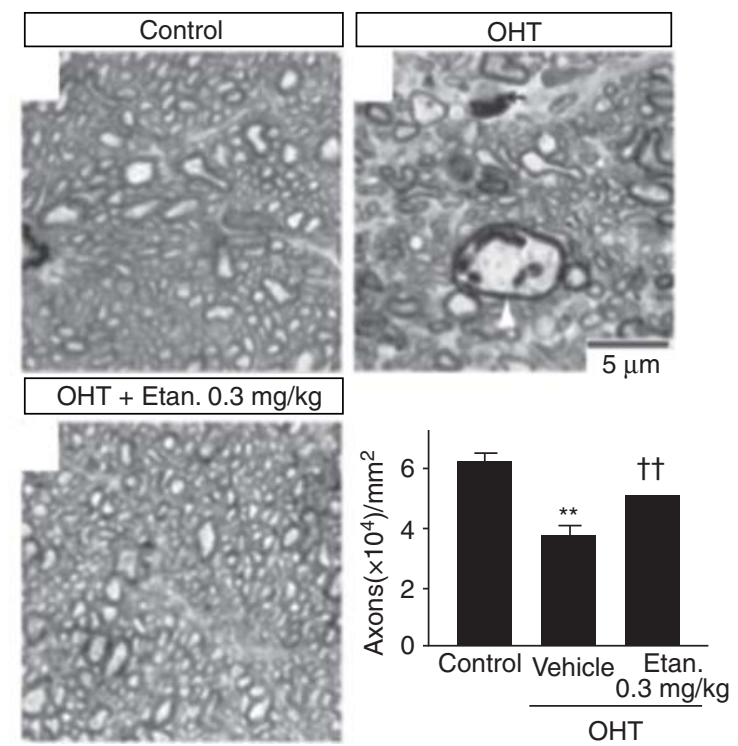

Figure 3. Inhibition of TNF- $\alpha$ activity reduces microglial activation and axonal degeneration in the optic nerve after ocular hypertension. (A) Ocular hypertension (OHT) increased the number of Iba-1-positive microglial cells in the ONH and induced TNF- $\alpha$ expression in these cells. Treatment with the TNF- $\alpha$ inhibitor Etanercept (Etan.) significantly reduced the number of microglia and the expression of TNF- $\alpha$. (B) Axonal degeneration in the optic nerve is reduced by Etanercept treatment in ocular hypertension (Roh et al. 2012). Mann-Whitney $\mathrm{U}$ test, ${ }^{* *} P<0.01$ comparing control vs. Etanercept treated ocular hypertension; $\dagger \dagger P<0.01$ comparing vehicle vs. Etanercept treated OHT. (Adapted from data in Roh et al. 2012.)

studies are needed to identify the precise roles of the different cell types at different stages of disease, keeping in mind that inflammatory molecules can mediate both damaging and beneficial responses.

\section{Transendothelial Migration of Leukocytes in Glaucoma}

One of the earliest processes to be significantly up-regulated in our transcriptional profiling of DBA/2J mice was transendothelial migration of leukocytes (Howell et al. 2012). In DBA/2J glaucoma, up-regulation of selectins (e.g., Pselectin), adhesion molecules (e.g. VCAM-1) and chemokines (e.g., CCL2) was observed at early stages of disease (Howell et al. 2012). Flow cytometry experiments confirmed the entry of monocyte-derived cells into the ONH (Fig. 4A)
(Howell et al. 2012). No other type of immune cell (including $\mathrm{B}$ cells or $\mathrm{T}$ cells) was found in DBA/2J glaucomatous tissue, although one study has shown B cells in human glaucomatous retinas (Gramlich et al. 2013). Monocyte infiltration was apparently blocked by DBA/2J mice treated with radiation (Fig. 4B) indicating that monocyte infiltration could be an important mediator of RGC and axonal damage in glaucoma (Howell et al. 2012). In support of this, a second study using a different experimental mouse model of glaucoma found that deletion of CD11b prevented the activation of monocyte-derived cells and loss of RGCs after induction of high IOP (Nakazawa et al. 2006). However, this study was not able to distinguish between resident microglia and infiltrating monocytes. The mechanism(s) by which monocytes affect RGCs in glaucoma has not been 

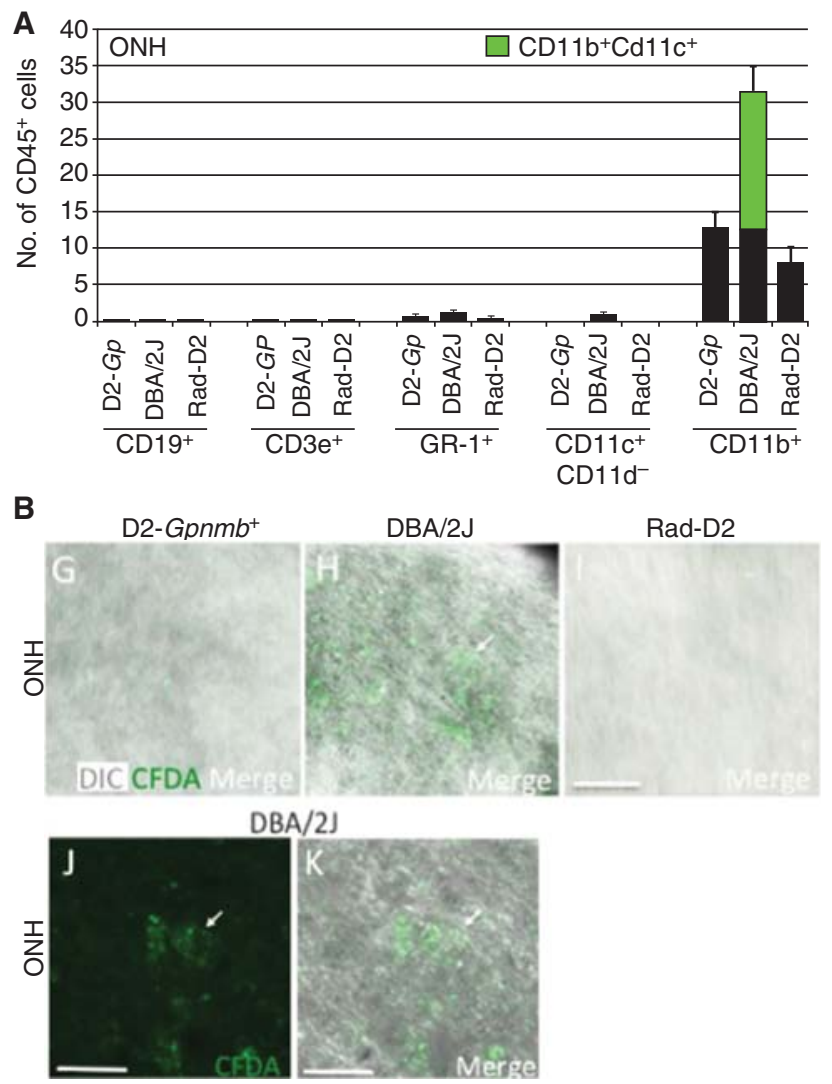

Figure 4. Monocyte infiltration occurs early in DBA/2J glaucoma. (A) Flow cytometry revealed that the major blood-derived immune cell detected in the $\mathrm{ONH}$ of DBA/2J glaucomatous mice was the $\mathrm{CD}_{11} \mathrm{~b}^{+} \mathrm{Cd} 11 \mathrm{c}^{+}$ monocyte. These cells were completely absent in radiation-treated DBA/2J eyes (Rad-D2) or control (D2-Gp) eyes. (B) Cell infiltration was also assessed using the injection of a fluorescent tracer into the spleen (CFDA, green). Spleen-derived $\mathrm{CFDA}^{+}$cells entered the optic nerves of untreated DBA/2J eyes but not Rad-D2 eyes or control eyes (Howell et al. 2012). (From Howell et al. 2013; adapted, with permission, from the authors.)

elucidated and further studies are needed to define the contribution of these infiltrating monocytes in glaucoma progression.

\section{The Complement Cascade in Glaucoma}

Components of the complement cascade are induced in human and animal models of glaucoma, suggesting a key role for this system in progression of the disease (Ahmed et al. 2004; Kuehn et al. 2006, 2008; Stasi et al. 2006; Steele et al. 2006; Stevens et al. 2007; Ren and Danias 2010; Tezel et al. 2010; Howell et al. 2011a). In experimental models of glaucoma, induction of complement components in the retina and
$\mathrm{ONH}$ was one of the earliest signaling responses to high IOP (Howell et al. 2011a; Johnson et al. 2011). Up-regulation of Clqa, a member of the $\mathrm{C} 1$ complex that triggers activation of the classical pathway, was observed in microglial cells in the $\mathrm{ONH}$ before detection of axonal damage in DBA/2J glaucomatous mice (Howell et al. 2011a). Deposition of C1QA protein was also observed in RGC dendrites in glaucomatous $\mathrm{DBA} / 2 \mathrm{~J}$ retinas as well as in primate and human glaucomatous retinas (Fig. 5A) (Kuehn et al. 2006; Stasi et al. 2006; Stevens et al. 2007; Tezel et al. 2010), suggesting an involvement of the complement cascade in pathological synapse elimination and/or dendrite remodeling in 
A
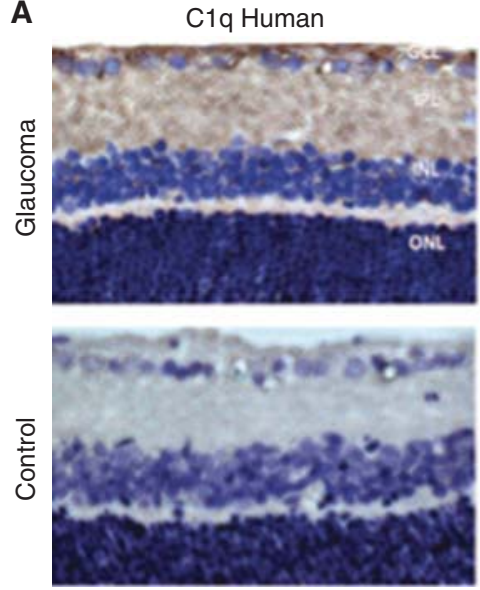

B
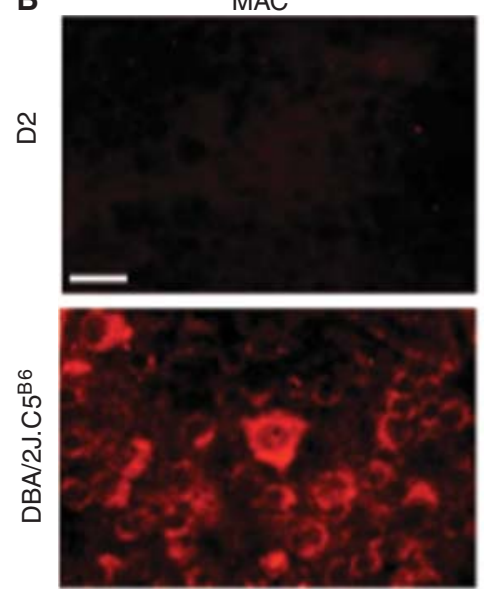
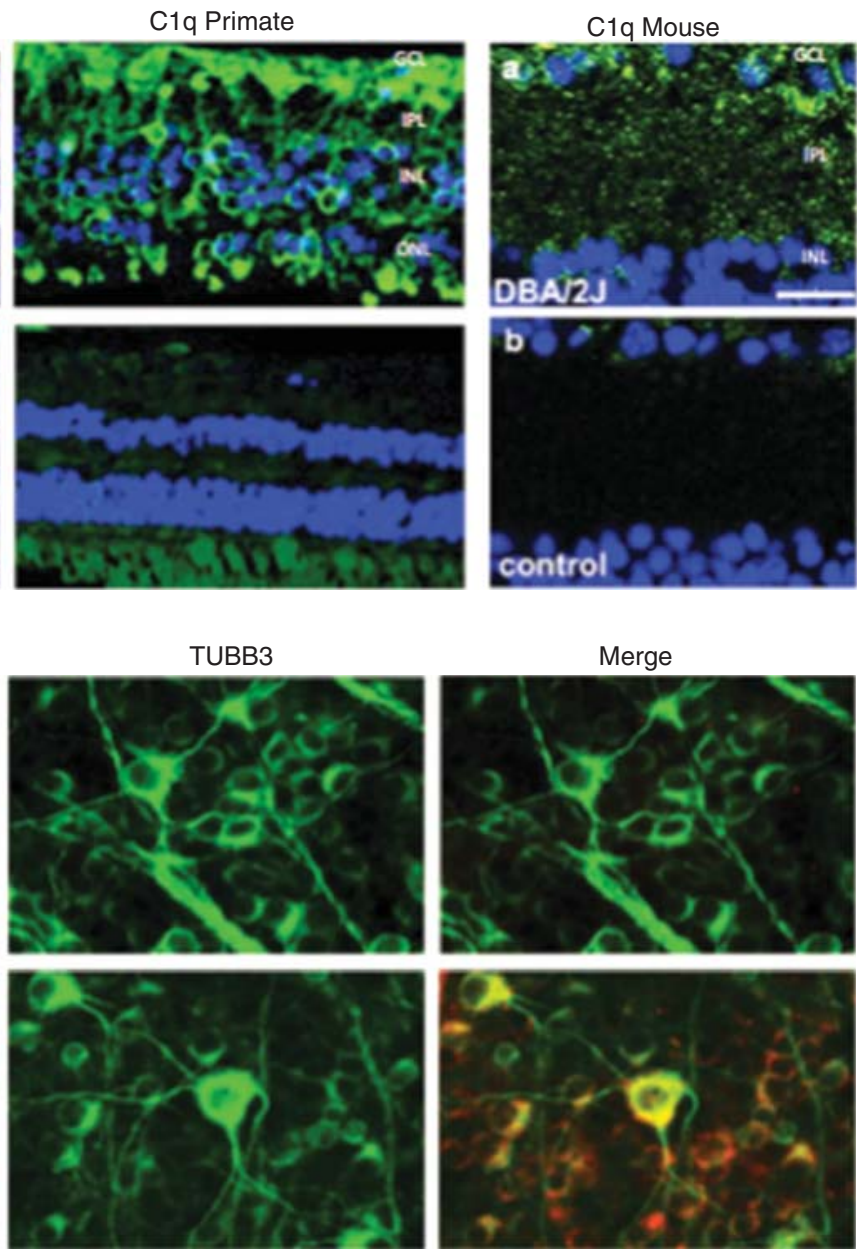

NOE $10.5 \mathrm{mo}$

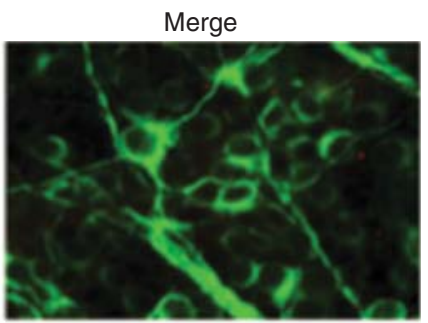

Figure 5. The complement system is activated in human and animal models of glaucoma. $(A)$ C1Q protein is increased in RGCs and in the inner plexiform layer of human (Tezel et al. 2010), primate (Stasi et al. 2006), and mouse (Howell et al. 2011a) retinas in response to high IOP. (B) MAC deposition is found in RGCs from C5sufficient glaucomatous DBA/2J.C5 ${ }^{\mathrm{B} 6}$ mice (Howell et al. 2013). TUBB3, tubulin $\beta-3$; NOE, normal or early.

glaucoma. Importantly, DBA/2J mice deficient in C1QA were protected from glaucomatous RGC loss, demonstrating an important and damaging contribution for C1qa in glaucoma (Howell et al. 2011a).

A second component of the complement cascade that likely plays a damaging role in glaucoma is complement component C5, a necessary component in generation of the MAC. Significant deposition of MAC was found in glaucomatous RGCs in human eyes and in experimental models of glaucoma (Kuehn et al. 2006; Jha et al. 2011; Howell et al. 2013). Drug inhibition of complement activation reduced MAC deposition and apoptosis of RGCs in a rat model of glaucoma (Jha et al. 2011). Furthermore, C5-deficient DBA/2J mice showed reduced neurodegeneration compared with $\mathrm{C} 5$-sufficient DBA/2J mice (Howell et al. 2013). Although it is not clear how C5 contributes to glaucoma, significant deposition of MACs was observed in RGCs and in dystrophic neurites in the optic 


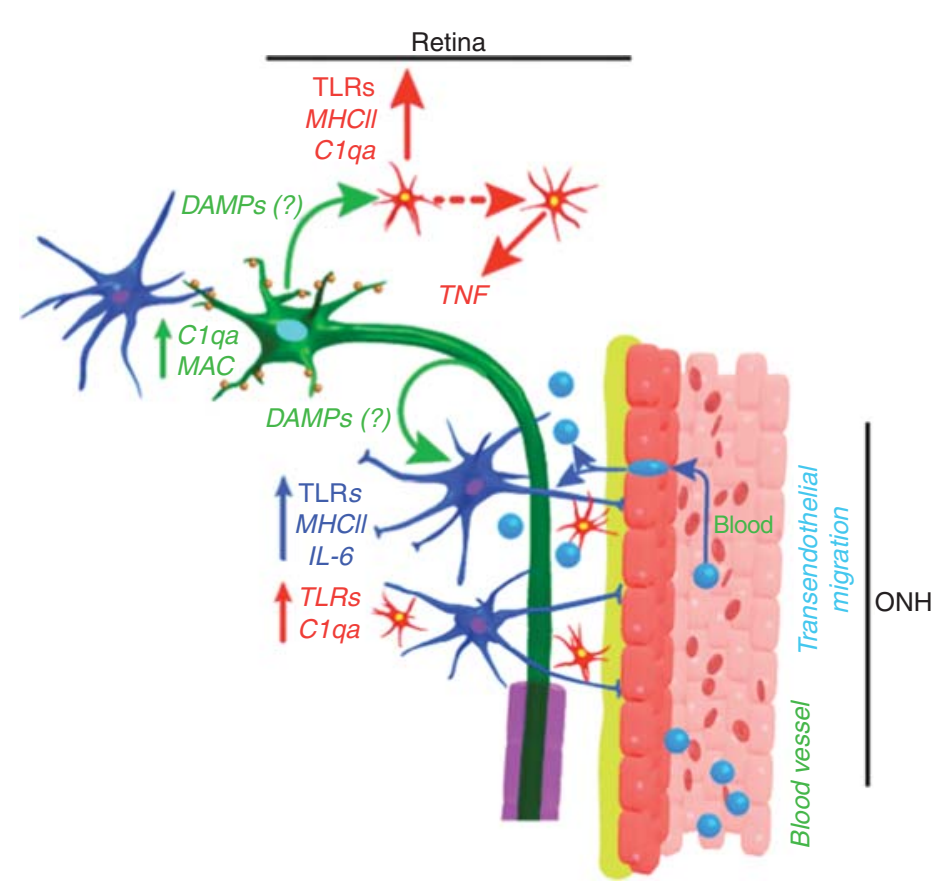

Figure 6. A model of early neuroinflammatory responses in glaucoma. We hypothesize that initiation of these immune responses occurs after the release of DAMPs from RGCs, glial cells or both. The TLRs expressed in glial cells activate the production and secretion of cytokines such as those of the IL-1 family. A secondary expression of cytokines, such as TNF- $\alpha$ in microglia and IL- 6 in astrocytes, is induced, leading to an amplified inflammatory response. These neuroinflammatory responses are likely modulated by complement proteins, such as C1qa, in the ONH. In addition, intrinsic up-regulation of complement molecules in RGCs (such as C1qa and C3) occurs early and mediates synaptic dysfunction. The cell types shown here are described in the legend for Figure 1.

nerve (Fig. 5B), suggesting a detrimental contribution of $\mathrm{C} 5 \mathrm{~b}$ to glaucoma progression.

Much work is being done (in our laboratory, the Danias laboratory, and others) regarding the role of the complement cascade in glaucoma. Areas of active research include assessment of other key components of the cascade such as C3 and C4. Complement proteins are expressed in multiple cell types and it will be important to understand the cell-specific roles of complement components in glaucoma.

\section{CONCLUDING REMARKS}

In recent years a critical role for neuroinflammatory processes mediated by astrocytes, microglia, endothelial cells, infiltrating monocytes and other cell types in the pathogenesis of glaucoma has been demonstrated (Fig. 6). However, many challenges remain. The potential for beneficial and detrimental inflammatory processes occurring at different stages of glaucoma make developing therapies that target these processes a complex but, in our view, solvable problem. Furthermore, these cells do not function in isolation, and understanding the changes to the neurovascular unit as a whole will also be critical. Development of a detailed spatial and temporal understanding of these neuroinflammatory events in humans and in multiple animal models is critical as we move toward new neuroprotective treatments for human glaucoma.

\section{ACKNOWLEDGMENTS}

The authors thank Pete Williams and Jeffrey Harder for critical comments. This work was supported by The Glaucoma Foundation (GRH) and EY021525 (GRH). 
I. Soto and G.R. Howell

\section{REFERENCES}

Ahmed F, Brown KM, Stephan DA, Morrison JC, Johnson EC, Tomarev SI. 2004. Microarray analysis of changes in mRNA levels in the rat retina after experimental elevation of intraocular pressure. Invest Ophthalmol Vis Sci 45: $1247-1258$.

Bonifati DM, Kishore U. 2007. Role of complement in neurodegeneration and neuroinflammation. Mol Immunol 44: 999-1010

Bosco A, Steele MR, Vetter ML. 2011. Early microglia activation in a mouse model of chronic glaucoma. J Comp Neurol 519: 599-620.

Bosco A, Crish SD, Steele MR, Romero CO, Inman DM, Horner PJ, Calkins DJ, Vetter ML. 2012. Early reduction of microglia activation by irradiation in a model of chronic glaucoma. PLoS ONE 7: e43602.

Burgoyne CF. 2011. A biomechanical paradigm for axonal insult within the optic nerve head in aging and glaucoma. Exp Eye Res 93: 120-132.

Callahan MK, Ransohoff RM. 2004. Analysis of leukocyte extravasation across the blood-brain barrier: Conceptual and technical aspects. Curr Allergy Asthma Rep 4: $65-73$

Carson MJ, Doose JM, Melchior B, Schmid CD, Ploix CC. 2006. CNS immune privilege: Hiding in plain sight. Immunol Rev 213: 48-65.

Downes CE, Crack PJ. 2010. Neural injury following stroke: Are Toll-like receptors the link between the immune system and the CNS? Br J Pharmacol 160: 1872-1888.

Ebneter A, Casson RJ, Wood JP, Chidlow G. 2010. Microglial activation in the visual pathway in experimental glauco ma: Spatiotemporal characterization and correlation with axonal injury. Invest Ophthalmol Vis Sci 51: 6448 6460 .

Farina C, Aloisi F, Meinl E. 2007. Astrocytes are active players in cerebral innate immunity. Trends Immunol 28: 138145.

Gazi U, Martinez-Pomares L. 2009. Influence of the mannose receptor in host immune responses. Immunobiology 214: $554-561$.

Ginhoux F, Greter M, Leboeuf M, Nandi S, See P, Gokhan S, Mehler MF, Conway SJ, Ng LG, Stanley ER, et al. 2010 Fate mapping analysis reveals that adult microglia derive from primitive macrophages. Science 330: 841-845.

Glass CK, Saijo K, Winner B, Marchetto MC, Gage FH. 2010. Mechanisms underlying inflammation in neurodegeneration. Cell 140: 918-934.

Gorina R, Santalucia T, Petegnief V, Ejarque-Ortiz A, Saura J, Planas AM. 2009. Astrocytes are very sensitive to develop innate immune responses to lipid-carried short interfering RNA. Glia 57: 93-107.

Gramlich OW, Beck S, von Thun Und Hohenstein-Blaul N, Boehm N, Ziegler A, Vetter JM, Pfeiffer N, Grus FH. 2013. Enhanced insight into the autoimmune component of glaucoma: IgG autoantibody accumulation and pro-inflammatory conditions in human glaucomatous retina. PloS ONE 8: e57557.

Gregory MS, Hackett CG, Abernathy EF, Lee KS, Saff RR, Hohlbaum AM, Moody KS, Hobson MW, Jones A, Kolovou P, et al. 2011. Opposing roles for membrane bound and soluble Fas ligand in glaucoma-associated retinal ganglion cell death. PLoS ONE 6: e17659.

Hernandez MR, Andrzejewska WM, Neufeld AH. 1990. Changes in the extracellular matrix of the human optic nerve head in primary open-angle glaucoma. Am J Ophthalmol 109: 180-188.

Hernandez MR, Ye H, Roy S. 1994. Collagen type IV gene expression in human optic nerve heads with primary open angle glaucoma. Exp Eye Res 59: 41-51.

Hernandez MR, Miao H, Lukas T. 2008. Astrocytes in glaucomatous optic neuropathy. Prog Brain Res 173: $353-$ 373.

Herrmann JE, Imura T, Song B, Qi J, Ao Y, Nguyen TK, Korsak RA, Takeda K, Akira S, Sofroniew MV. 2008. STAT3 is a critical regulator of astrogliosis and scar formation after spinal cord injury. J Neurosci 28: 72317243.

Howell GR, Libby RT, Jakobs TC, Smith RS, Phalan FC, Barter JW, Barbay JM, Marchant JK, Mahesh N, Porciatti V, et al. 2007. Axons of retinal ganglion cells are insulted in the optic nerve early in DBA/2J glaucoma. J Cell Biol 179: $1523-1537$.

Howell GR, Macalinao DG, Sousa GL, Walden M, Soto I, Kneeland SC, Barbay JM, King BL, Marchant JK, Hibbs M, et al. 2011a. Molecular clustering identifies complement and endothelin induction as early events in a mouse model of glaucoma. J Clin Invest 121: 1429-1444.

Howell GR, Walton DO, King BL, Libby RT, John SW. 2011 b. Datgan, a reusable software system for facile interrogation and visualization of complex transcription profiling data. BMC Genomics 12: 429.

Howell GR, Soto I, Zhu X, Ryan M, Macalinao DG, Sousa GL, Caddle LB, MacNicoll KH, Barbay JM, Porciatti V, et al. 2012. Radiation treatment inhibits monocyte entry into the optic nerve head and prevents neuronal damage in a mouse model of glaucoma. J Clin Invest 122: 12461261.

Howell GR, Soto I, Ryan M, Graham LC, Smith RS, John SW. 2013. Deficiency of complement component 5 ameliorates glaucoma in DBA/2J mice. J Neuroinflammation 10: 76.

Husemann J, Loike JD, Anankov R, Febbraio M, Silverstein SC. 2002. Scavenger receptors in neurobiology and neuropathology: Their role on microglia and other cells of the nervous system. Glia 40: 195-205.

Iadecola C, Nedergaard M. 2007. Glial regulation of the cerebral microvasculature. Nat Neurosci 10: 1369-1376.

Ifergan I, Kebir H, Bernard M, Wosik K, Dodelet-Devillers A, Cayrol R, Arbour N, Prat A. 2008. The blood-brain barrier induces differentiation of migrating monocytes into Th17-polarizing dendritic cells. Brain 131: 785-799.

Inman DM, Horner PJ. 2007. Reactive nonproliferative gliosis predominates in a chronic mouse model of glaucoma. Glia 55: $942-953$

Jakobs TC, Libby RT, Ben Y, John SWM, Masland RH. 2005. Retinal ganglion cell degeneration is topological but not cell type specific in DBA/2J mice. J Cell Biol 171: 313 325.

Janeway CA, Travers P, Walport M, Shlomchik M. 2001. Immunobiology: The Immune System in Health and Disease 5th edition. Garland Science, New York. 
Jha P, Banda H, Tytarenko R, Bora PS, Bora NS. 2011. Complement mediated apoptosis leads to the loss of retinal ganglion cells in animal model of glaucoma. Mol Immunol 48: 2151-2158.

Johnson EC, Deppmeier LM, Wentzien SK, Hsu I, Morrison JC. 2000. Chronology of optic nerve head and retinal responses to elevated intraocular pressure. Invest Ophthalmol Vis Sci 41: 431-442.

Johnson EC, Doser TA, Cepurna WA, Dyck JA, Jia L, Guo Y, Lambert WS, Morrison JC. 2011. Cell proliferation and interleukin-6-type cytokine signaling are implicated by gene expression responses in early optic nerve head injury in rat glaucoma. Invest Ophthalmol Vis Sci 52: 504-518.

Johnson EC, Jia L, Cepurna WA, Doser TA, Morrison JC. 2007. Global changes in optic nerve head gene expression after exposure to elevated intraocular pressure in a rat glaucoma model. Invest Ophthalmol Vis Sci 48: 31613177.

Johnson EC, Morrison JC. 2009. Friend or foe? Resolving the impact of glial responses in glaucoma. J Glaucoma 18: 341-353.

Kerrigan AM, Brown GD. 2009. C-type lectins and phagocytosis. Immunobiology 214: 562-575.

Kompass KS, Agapova OA, Li W, Kaufman PL, Rasmussen CA, Hernandez MR. 2008. Bioinformatic and statistical analysis of the optic nerve head in a primate model of ocular hypertension. BMC Neurosci 9: 93.

Kono H, Rock KL. 2008. How dying cells alert the immune system to danger. Nat Rev Immunol 8: 279-289.

Kuehn MH, Kim CY, Ostojic J, Bellin M, Alward WL, Stone EM, Sakaguchi DS, Grozdanic SD, Kwon YH. 2006. Retinal synthesis and deposition of complement components induced by ocular hypertension. Exp Eye Res 83: 620-628.

Kuehn MH, Kim CY, Jiang B, Dumitrescu AV, Kwon YH. 2008. Disruption of the complement cascade delays retinal ganglion cell death following retinal ischemia-reperfusion. Exp Eye Res 87: 89-95.

Lampron A, Elali A, Rivest S. 2013. Innate immunity in the CNS: Redefining the relationship between the CNS and its environment. Neuron 78: 214-232.

Lehnardt S. 2010. Innate immunity and neuroinflammation in the CNS: The role of microglia in Toll-like receptormediated neuronal injury. Glia 58: 253-263.

Luo C, Yang X, Kain AD, Powell DW, Kuehn MH, Tezel G. 2010. Glaucomatous tissue stress and the regulation of immune response through glial Toll-like receptor signaling. Invest Ophthalmol Vis Sci 51: 5697-5707.

Lye-Barthel M, Sun D, Jakobs TC. 2013. Morphology of astrocytes in a glaucomatous optic nerve. Invest Ophthalmol Vis Sci 54: 909-917.

Midwood K, Sacre S, Piccinini AM, Inglis J, Trebaul A, Chan E, Drexler S, Sofat N, Kashiwagi M, Orend G, et al. 2009. Tenascin-C is an endogenous activator of Toll-like receptor 4 that is essential for maintaining inflammation in arthritic joint disease. Nat Med 15: 774-780.

Morrison JC, Dorman-Pease ME, Dunkelberger GR, Quigley HA. 1990. Optic nerve head extracellular matrix in primary optic atrophy and experimental glaucoma. Arch Ophthalmol 108: 1020-1024.
Nakazawa T, Nakazawa C, Matsubara A, Noda K, Hisatomi T, She H, Michaud N, Hafezi-Moghadam A, Miller JW, Benowitz LI. 2006. Tumor necrosis factor- $\alpha$ mediates oligodendrocyte death and delayed retinal ganglion cell loss in a mouse model of glaucoma. $J$ Neurosci 26: 12633-12641.

Neufeld AH. 1999. Microglia in the optic nerve head and the region of parapapillary chorioretinal atrophy in glaucoma. Arch Ophthalmol 117: 1050-1056.

Nickells RW, Howell GR, Soto I, John SW. 2012. Under pressure: Cellular and molecular responses during glaucoma, a common neurodegeneration with axonopathy. Annu Rev Neurosci 35: 153-179.

Nikolskaya T, Nikolsky Y, Serebryiskaya T, Zvereva S, Sviridov E, Dezso Z, Rahkmatulin E, Brennan RJ, Yankovsky N, Bhattacharya SK, et al. 2009. Network analysis of human glaucomatous optic nerve head astrocytes. $B M C$ Med Genomics 2: 24.

Okada S, Nakamura M, Katoh H, Miyao T, Shimazaki T, Ishii K, Yamane J, Yoshimura A, Iwamoto Y, Toyama Y, et al. 2006. Conditional ablation of Stat3 or Socs3 discloses a dual role for reactive astrocytes after spinal cord injury. Nat Med 12: 829-834.

Panagis L, Zhao X, Ge Y, Ren L, Mittag TW, Danias J. 2010. Gene expression changes in areas of focal loss of retinal ganglion cells in the retina of DBA/2J mice. Invest Ophthalmol Vis Sci 51: 2024-2034.

Pellerin L, Bouzier-Sore AK, Aubert A, Serres S, Merle M, Costalat R, Magistretti PJ. 2007. Activity-dependent regulation of energy metabolism by astrocytes: An update. Glia 55: 1251-1262.

Pena JD, Varela HJ, Ricard CS, Hernandez MR. 1999. Enhanced tenascin expression associated with reactive astrocytes in human optic nerve heads with primary open angle glaucoma. Exp Eye Res 68: 29-40.

Piccio L, Rossi B, Scarpini E, Laudanna C, Giagulli C, Issekutz AC, Vestweber D, Butcher EC, Constantin G. 2002. Molecular mechanisms involved in lymphocyte recruitment in inflamed brain microvessels: Critical roles for P-selectin glycoprotein ligand-1 and heterotrimeric $\mathrm{G}_{\mathrm{i}}-$-linked receptors. J Immunol 168: 1940-1949.

Qu J, Jakobs TC. 2013. The time course of gene expression during reactive gliosis in the optic nerve. PloS ONE 8: e67094.

Quigley HA. 1993. Open-angle glaucoma. New Engl J Med 328: 1097-1106.

Quigley HA. 2011. Glaucoma. Lancet 377: 1367-1377.

Ransohoff RM, Brown MA. 2012. Innate immunity in the central nervous system. J Clin Invest 122: 1164-1171.

Ransohoff RM, Engelhardt B. 2012. The anatomical and cellular basis of immune surveillance in the central nervous system. Nat Rev Immunol 12: 623-635.

Ransohoff RM, Kivisakk P, Kidd G. 2003. Three or more routes for leukocyte migration into the central nervous system. Nat Rev Immunol 3: 569-581.

Ren L, Danias J. 2010. A role for complement in glaucoma? Adv Exp Med Biol 703: 95-104.

Ricklin D, Hajishengallis G, Yang K, Lambris JD. 2010. Complement: A key system for immune surveillance and homeostasis. Nat Immunol 11: 785-797. 
I. Soto and G.R. Howell

Rifkin IR, Leadbetter EA, Busconi L, Viglianti G, MarshakRothstein A. 2005. Toll-like receptors, endogenous ligands, and systemic autoimmune disease. Immunol Rev 204: 27-42.

Roh M, Zhang Y, Murakami Y, Thanos A, Lee SC, Vavvas DG, Benowitz LI, Miller JW. 2012. Etanercept, a widely used inhibitor of tumor necrosis factor- $\alpha$ (TNF- $\alpha$ ), prevents retinal ganglion cell loss in a rat model of glaucoma. PloS ONE 7: e40065.

Rosen AM, Stevens B. 2010. The role of the classical complement cascade in synapse loss during development and glaucoma. Adv Exp Med Biol 703: 75-93.

Rouach N, Koulakoff A, Abudara V, Willecke K, Giaume C. 2008. Astroglial metabolic networks sustain hippocampal synaptic transmission. Science 322: 1551-1555.

Sawada H, Fukuchi T, Tanaka T, Abe H. 2010. Tumor necrosis factor- $\alpha$ concentrations in the aqueous humor of patients with glaucoma. Invest Ophthalmol Vis Sci 51: 903 906.

Schlamp CL, Li Y, Dietz JA, Janssen KT, Nickells RW. 2006. Progressive ganglion cell loss and optic nerve degeneration in DBA/2J mice is variable and asymmetric. $B M C$ Neurosci 7: 66

Simard M, Nedergaard M. 2004. The neurobiology of glia in the context of water and ion homeostasis. Neuroscience 129: $877-896$

Sofroniew MV, Vinters HV. 2010. Astrocytes: Biology and pathology. Acta Neuropathol 119: 7-35.

Soto I, Oglesby E, Buckingham BP, Son JL, Roberson EDO, Steele MR, Inman DM, Vetter ML, Horner PJ, MarshArmstrong N. 2008. Retinal ganglion cells downregulate gene expression and lose their axons within the optic nerve head in a mouse glaucoma model. J Neurosci 28: $548-561$.

Stasi K, Nagel D, Yang X, Wang RF, Ren L, Podos SM, Mittag T, Danias J. 2006. Complement component 1Q (C1Q) upregulation in retina of murine, primate, and human glaucomatous eyes. Invest Ophthalmol Vis Sci 47: 10241029.

Steele MR, Inman DM, Calkins DJ, Horner PJ, Vetter ML. 2006. Microarray analysis of retinal gene expression in the DBA/2J model of glaucoma. Invest Ophthalmol Vis Sci 47: $977-985$

Stevens B, Allen NJ, Vazquez LE, Howell GR, Christopherson KS, Nouri N, Micheva KD, Mehalow AK, Huberman AD, Stafford B, et al. 2007. The classical complement cascade mediates CNS synapse elimination. Cell 131: 1164-1178.

Sun D, Qu J, Jakobs TC. 2013. Reversible reactivity by optic nerve astrocytes. Glia 61: 1218-1235.

Takeuchi O, Akira S. 2010. Pattern recognition receptors and inflammation. Cell 140: 805-820.

Tanigami H, Okamoto T, Yasue Y, Shimaoka M. 2012. Astroglial integrins in the development and regulation of neurovascular units. Pain Res Treat 2012: 964652.

Taylor S, Calder CJ, Albon J, Erichsen JT, Boulton ME, Morgan JE. 2011. Involvement of the CD200 receptor complex in microglia activation in experimental glaucoma. Exp Eye Res 92: 338-343.
Tezel G. 2011. The immune response in glaucoma: A perspective on the roles of oxidative stress. Exp Eye Res 93: $178-186$.

Tezel G. 2013. Immune regulation toward immunomodulation for neuroprotection in glaucoma. Curr Opin Pharmacol 13: 23-31.

Tezel G, Li LY, Patil RV, Wax MB. 2001. TNF- $\alpha$ and TNF- $\alpha$ receptor-1 in the retina of normal and glaucomatous eyes. Invest Ophthalmol Vis Sci 42: 1787-1794.

Tezel G, Yang J, Wax MB. 2004. Heat shock proteins, immunity and glaucoma. Brain Res Bull 62: 473-480.

Tezel G, Yang X, Luo C, Kain AD, Powell DW, Kuehn MH, Kaplan HJ. 2010. Oxidative stress and the regulation of complement activation in human glaucoma. Invest Ophthalmol Vis Sci 51: 5071-5082.

Tezel G, Yang X, Luo C, Cai J, Powell DW. 2012. An astrocytespecific proteomic approach to inflammatory responses in experimental rat glaucoma. Invest Ophthalmol Vis Sci 53: $4220-4233$.

Ullian EM, Sapperstein SK, Christopherson KS, Barres BA. 2001. Control of synapse number by glia. Science 291: 657-661.

Wang L, Cioffi GA, Cull G, Dong J, Fortune B. 2002. Immunohistologic evidence for retinal glial cell changes in human glaucoma. Invest Ophthalmol Vis Sci 43: 10881094.

Yan X, Tezel G, Wax MB, Edward DP. 2000. Matrix metalloproteinases and tumor necrosis factor $\alpha$ in glaucomatous optic nerve head. Arch Ophthalmol 118: 666-673.

Yang Z, Quigley HA, Pease ME, Yang Y, Qian J, Valenta D, Zack DJ. 2007. Changes in gene expression in experimental glaucoma and optic nerve transection: The equilibrium between protective and detrimental mechanisms. Invest Ophthalmol Vis Sci 48: 5539-5548.

Yang X, Luo C, Cai J, Powell DW, Yu D, Kuehn MH, Tezel G. 2011. Neurodegenerative and inflammatory pathway components linked to TNF- $\alpha /$ TNFR1 signaling in the glaucomatous human retina. Invest Ophthalmol Vis Sci 52: 8442-8454.

Yuan L, Neufeld AH. 2000. Tumor necrosis factor- $\alpha$ : A potentially neurodestructive cytokine produced by glia in the human glaucomatous optic nerve head. Glia 32: $42-$ 50.

Yuan L, Neufeld AH. 2001. Activated microglia in the human glaucomatous optic nerve head. J Neurosci Res 64 $523-532$.

Yu L, Wang L, Chen S. 2010. Endogenous toll-like receptor ligands and their biological significance. J Cell Mol Med 14: $2592-2603$.

Zhang Q, Raoof M, Chen Y, Sumi Y, Sursal T, Junger W, Brohi K, Itagaki K, Hauser CJ. 2010. Circulating mitochondrial DAMPs cause inflammatory responses to injury. Nature 464: 104-107.

Zhu H, Wang L, Ruan Y, Zhou L, Zhang D, Min Z, Xie J, Yu M, Gu J. 2011. An efficient delivery of DAMPs on the cell surface by the unconventional secretion pathway. Biochem Biophys Res Commun 404: 790-795. 


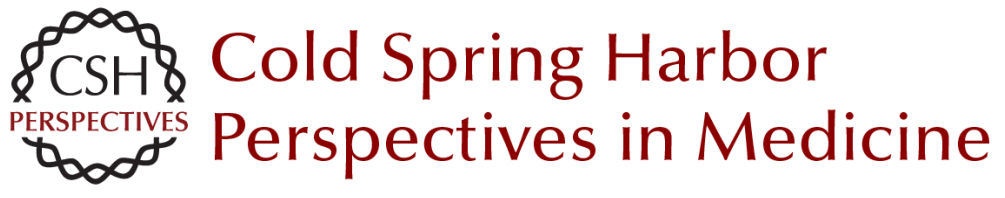

\section{The Complex Role of Neuroinflammation in Glaucoma}

lleana Soto and Gareth R. Howell

Cold Spring Harb Perspect Med 2014; doi: 10.1101/cshperspect.a017269 originally published online July 3, 2014

\section{Subject Collection Retinal Disorders: Genetic Approaches to Diagnosis and Treatment}

Trial by "Firsts": Clinical Trial Design and Regulatory Considerations in the Development and Approval of the First AAV Gene Therapy Product in the United States

Kathleen Z. Reape and Katherine A. High

Immunology of Retinitis Pigmentosa and Gene Therapy-Associated Uveitis

Paul Yang, Debarshi Mustafi and Kathryn L. Pepple

Developing New Vectors for Retinal Gene Therapy Emilia A. Zin, Bilge E. Ozturk, Deniz Dalkara, et al.

Beyond the NEI-VFQ: Recent Experience in the Development and Utilization of Patient-Reported Outcomes for Inherited Retinal Diseases

Todd Durham, Judit Banhazi, Francesco Patalano, et al.

Electronic Retinal Prostheses

Daniel Palanker

Alternative RNA Splicing in the Retina: Insights and Perspectives

Casey J. Keuthan, Sadik Karma and Donald J. Zack

X-Linked Retinoschisis

Cristy A. Ku, Lisa W. Wei and Paul A. Sieving

A Systematic Review of Optogenetic Vision Restoration: History, Challenges, and New Inventions from Bench to Bedside

Antonia Stefanov and John G. Flannery
Lessons Learned from the Development of the

First FDA-Approved Gene Therapy Drug,

Voretigene Neparvovec-rzyl Jean Bennett and Albert M. Maguire

Therapeutic Gene Editing in Inherited Retinal Disorders Jinjie Ling, Laura A. Jenny, Ashley Zhou, et al.

Cell-Based Therapies: Strategies for Regeneration Marina Pavlou and Thomas A. Reh

The Importance of Natural History Studies in Inherited Retinal Diseases

Allison Ayala, Janet Cheetham, Todd Durham, et al.

Photoreceptor Cell Replacement Using

Pluripotent Stem Cells: Current Knowledge and Remaining Questions

Christelle Monville, Olivier Goureau and Karim Ben M'Barek

iPSC-RPE in Retinal Degeneration: Recent

Advancements and Future Perspectives

Tadao Maeda and Masayo Takahashi

Retinal Degeneration Animal Models in Bardet-

Biedl Syndrome and Related Ciliopathies Clarisse Delvallée and Hélène Dollfus

Mobility Testing and Other Performance-Based

Assessments of Functional Vision in Patients with Inherited Retinal Disease

Daniel Chung, Colas Authié and Laure Blouin

For additional articles in this collection, see http://perspectivesinmedicine.cshlp.org/cgi/collection/ 
For additional articles in this collection, see http://perspectivesinmedicine.cshlp.org/cgi/collection/ 